\title{
COMPLIANCE OF SELECTED STINGLESS BEE HONEY IN KELANTAN ACCORDING TO MALAYSIAN STANDARD (MS) 2683:2017
}

\author{
NOOR HAFIZOH SAIDAN ${ }^{1 *}$, NORSYAHIRA ROSLAN ${ }^{1}$, NUR RAHIIQIN MAKTUUM BAHARUDDIN, \\ MOHD SHAHRUL RIDZUAN HAMIL ${ }^{2}$ and KUMARA THEVAN KRISHNAN ${ }^{1}$ \\ ${ }^{1}$ Faculty of Agro Based Industry, Universiti Malaysia Kelantan, Jeli Campus, \\ 17600 Jeli, Kelantan, Malaysia \\ ${ }^{2}$ Discipline of Pharmaceutical Chemistry, School of Pharmaceutical Sciences, \\ Universiti Sains Malaysia, 11800 Minden, Penang, Malaysia \\ *E-mail: hafizoh.s@umk.edu.my
}

Accepted 26 November 2020, Published online 25 December 2020

\begin{abstract}
In Malaysia, commercial stingless bee honey is in demand due to its nutritional and healing properties, especially in the cosmetic, food and beverage and pharmaceutical industry. However, up to date, these honey products from various districts of Kelantan were not subjected to compliance according to the specification of the Malaysian Standard (MS) 2683:2017. Thus, the objective of the current study was to determine the compliance of selected stingless bee honey (SBH) in Kelantan based upon physicochemical properties and microbiological analysis following MS 2683:2017 specifications. Physicochemical analysis of commercial stingless be honey shows the value of moisture, ash, hydroxymethylfurfural (HMF) and $\mathrm{pH}$ were in the range of $27.05 \pm 1.39$ to $32.61 \pm 2.79 \%, 0.08 \pm 0.01$ to $0.14 \pm 0.01 \mathrm{~g}, 8.78 \pm 0.92$ to $218.66 \pm 0.70 \mathrm{mg} / \mathrm{kg}$ and $2.34 \pm 0.01$ to $3.22 \pm 0.02$, respectively. There was an absence of total coliform in all samples. In summary, all samples of stingless bee honey complied with MS 2683:2017 specification for physicochemical properties and microbial contaminant limits of total plate count (TPC) and total coliform. However, for the microbial contaminant limit of yeast and mold, only sample 6 was contaminated.
\end{abstract}

Key words: Physicochemical properties, microbial contaminant limits, stingless bee honey, Malaysian Standard 2683:2017

\section{INTRODUCTION}

Honey is defined as a natural sweet substance collecting from nectars flower by both honeybees (Apis spp.) and the stingless bee (Zainol, 2016). Based on the traditional medical practitioner, stingless bee or also known as 'kelulut' bee in Malaysia, having high medicinal values including antibacterial, anti-inflammatory and wound healing properties (Biswa et al., 2017). Stingless bee honey looks like a supersaturated sugar solution with colour ranges from nearly colourless to dark brown. It is mainly composed of a complex mixture of $80-85 \%$ carbohydrate (mainly glucose and fructose), $15-17 \%$ water, $0.1-0.4 \%$ protein, $0.2 \%$ ash and minor substances of minerals, amino acids, enzymes, vitamins, organic acids, lipids as well as other

\footnotetext{
* To whom correspondence should be addressed.
}

substances like phenolic antioxidants (Buba et al., 2013; Ummulkhair, 2014).

The phenolic compound is a secondary metabolite that consists of phenolic acid, flavones, flavonols, flavanones, flavanols, anthocyanidin, and isoflavones. The previous study reported that plant phenolic is a chemical component that acts as bioactivity in honey in terms of antioxidant capacity (Zainol, 2016; Da Silva et al., 2016). The component depends on the source of the flower that the bees collected the nectar. There are some cases regarding the infant botulism due to the presence of Clostridium botulinum in honey (Lani et al., 2017). Because of this issue, the FDA, the Centres for Disease Control and Prevention (CDC), and the American Academy of Paediatrics do not recommend honey to consume by infants (Lani et al., 2017). Honey might contaminate through primary sources including pollen, floral nectar, dust, 
soil, and the bodies and digestive tracts of bees or secondary sources including either during their extraction or processing (Ananias et al., 2013; Zainol, 2016; Lani et al., 2017).

In Malaysia, the issue of adultered honey is widespread in the market. Therefore, the standard guideline of stingless bee honey (MS 2683) was developed in the year 2017 through cooperation between institutions such as the Ministry of Science, Technology, and Innovation (MOSTI), Ministry of Agriculture and Agro-based Industry (MOA) and Department of Standards Malaysia. Based on this standard, honey products in the market should follow the guideline and specifications under Malaysian Standard 2683:2017 for the quality and safety of consumers (Kelulut (Stingless bee) honey - Specification Malaysian Standard MS 2683/: 2017). This study aimed to investigate the quality of selected stingless bee honey collected from various districts of Kelantan and its compliance to Malaysia Standard (MS) 2683:2107 specifications.

\section{MATERIALS AND METHODS}

\section{Chemicals and reagents}

The chemicals and reagents used in this study were sterile distilled water, sterile potassium dihydrogen phosphate anhydrous $\left(\mathrm{KH}_{2} \mathrm{PO}_{4}\right)$ (Bendosen), sterile plate count agar (PCA) (Himedia), sterile malt extract agar (MEA) (Himedia), sterile violet red bile agar (VRBA) (Himedia) and 70\% ethanol.

\section{Collection and preparation of stingless bee honey samples}

A total of thirteen stingless bee honey (Table 1) collected from different locations in Kelantan. The stingless bee honey samples refrigerated in temperature of $4-5^{\circ}$ in clean, dry, and airtight glass containers for further analysis. The details of the stingless bee honey, including the honey's location, type of honey, either raw or processed and either single or blended species, plant or pollen sources, date of harvesting, and their age, were collected from interviewing the beekeeper. The analysis was performed according to the procedure detailed in the Malaysian Standard 2683:2017 specification.

\section{Physicochemical analysis}

Physicochemical parameters were analyzed according to the methods recommended by the Malaysia Standard 2683:2017 (MS, 2017). These parameters included $\mathrm{pH}$, ash, hydroxymethylfurfural (HMF), and moisture content in stingless bee honey to undergo comparison assessment of honey samples to know the complying of standard guidelines in the market that reflects its quality.

\section{Determination of microbial contaminant limits analysis}

For the preparation of agar medium, Plate Count Agar (PCA) was used for the determination of TPC, Malt Extract Agar (MEA) for enumeration of yeast and molds, and Viable Red Bile Agar (VRBA) for determination of total coliform following Malaysian Standard MS 2683:2017. Initially, $10 \mathrm{~g}$ of sample was added into $90 \mathrm{~mL}$ of sterile potassium dihydrogen phosphate anhydrous $\left(\mathrm{KH}_{2} \mathrm{PO}_{4}\right)$ solution and was shaken for 25 times within $7 \mathrm{~s}$. Decimal dilutions of $10^{-1}, 10^{-2}, 10^{-3}$, and $10^{-4}$ were prepared by transferring $1.0 \mathrm{~mL}$ of the previous dilution to $9.0 \mathrm{~mL}$ of diluents. Separate sterile pipet tips were used for difference dilution. Then, $1 \mathrm{~mL}$ of each dilution was pipetted into duplicate separate Petri dishes. The previous preparation of agar was cooled to $45 \pm 1^{\circ}$. Then, 12 to $15 \mathrm{~mL}$ of agar was added to each plate and was mixed thoroughly and uniformly by using alternate rotation and back-and-forth motion on a flat level surface. The agar was let to solidify. For coliforms, another layer of agar was added onto previously solidified agar and was solidified. The solidified Petri dishes were inverted and were incubated promptly for $48 \pm 2 \mathrm{hr}$ at $27^{\circ}$ for TPC and total coliform while $72 \pm 2 \mathrm{hr}$ at $25^{\circ}$ for yeast and molds. The colonies were counted and recorded.

\section{Statistical analysis of data}

Statistical analysis was carried out with IBM Statistical Package for Social Sciences (SPSS) (SPSS Inc, U.S.A) version 21. Tukey's Honest Significant Different (HSD) test was conducted to evaluate the significant difference at a confidence level $(p<0.05)$ for physicochemical analysis and microbial contaminants limit test of different stingless bee honey.

Table 1. Stingless bee honey from a different location in Kelantan

\begin{tabular}{ccc}
\hline Honey sample & Honey type & Species \\
\hline 1 & Raw & Blended \\
2 & Process & Blended \\
3 & Raw & H. itama \\
4 & Raw & H. itama \\
5 & Raw & H. itama \\
6 & Raw & H. itama \\
7 & Raw & H. itama \\
8 & Raw & H. itama \\
9 & Raw & H. itama \\
10 & Raw & H. itama \\
11 & Raw & H. itama \\
12 & Raw & G. thoracica \\
13 & Raw & G. thoracica \\
\hline
\end{tabular}




\section{RESULTS AND DISCUSSION}

\section{Physicochemical analysis}

Physicochemical properties of stingless bee honey were performed for $\mathrm{pH}$, hydroxymethylfurfural (HMF), total ash, and moisture content. Table 1 showed the description of all stingless bee honey collected from different locations of Kelantan. Sample 2 was a process stingless bee honey, while samples 1 and 3 until 13 were raw stingless bee honey. Sample 1 is blended honey from species of Heterotrigona itama (H. itama), Geniotrigona thoracica (G. thoracica), Lepidotrigona terminata (L. terminata) and Tetragonula laeviceps ( $T$. laeviceps) while sample 2 is blended sample from species of G. thoracica, H. itama, and T. laeviceps. Stingless bee honey sample from a single species, either H. itama or G. thoracica.

Table 2 shows the $\mathrm{pH}$ of the stingless bee honey was ranged between $2.34 \pm 0.01$ to $3.22 \pm 0.02$. The highest acidity (low $\mathrm{pH}$ ) was sample number 2 (process, blended), and the lowest acidity was sample 7 (raw, single). Based on the $\mathrm{pH}$ result, all stingless bee honey is characterized as acidic. An independent test (HSD-test) shows that there is a significant difference $(p<0.05)$ of $\mathrm{pH}$ between all the stingless bee honey samples collected from various places of Kelantan. Sample 7 (raw, single) was honey collected from $H$. itama species has lower acidity compared with sample 13 (raw, single) collected from $G$. thoracica, which showed 3.22 and 2.87 , respectively. This similarity has been reported in other researches (Lani et al., 2017; Fadzelly et al., 2017), where it showed that the differences of $\mathrm{pH}$ in stingless bee honey were directly influenced by organic acids and mineral substances concentration (Lani et al., 2017). Low pH indicates more acidity and more hydrogen ion and organic acid involved in the formation of other compounds and sugar fermentation in stingless bee honey, which able to lowering the microbial content. High acidity able to inhibits microbial growth in the honey sample (Fatima et al., 2018; Fadzelly et al., 2017). The Malaysian Standard of stingless bee honey was set the limit of acceptable $\mathrm{pH}$ range from 2.5 to 3.8. Considering the range set by Malaysian Standard, all tested samples complied except sample 2 (process, blended) is too acidic compared to other samples.

Ash is one of the indicators of mineral collected by the bees during the flora foraging (Suntiparapop et al., 2012). Based on Table 2, it showed that all honey samples contain ash below the allowance limit specified by MS 2863:2017 with a value of not more than $1.0 \mathrm{~g} / 100 \mathrm{~g}$ for raw and processed honey. The range of ash content is between 0.08 to $0.14 \mathrm{~g} / 100 \mathrm{~g}$, concurred with the findings by Fadzelly et al. (2017). The highest value of ash content was sample 4, while the lowest value of ash was sample 8 . Both samples were harvested from H. itama species and had similar honey age of about three months. Hence, this show species and honey age do not affect the ash content. In addition, according to control sample 7 and 13 which comes from different bee species, Table 3 shows that there were no significant differences between samples $2,8,9,10,11$ and 12 to control sample 7 and also indicates significantly different between sample 12 and 13 . Hence, this can be concluded that all samples are not significant towards each other comparing to the control.

Hydroxymethylfurfural in stingless bee honey was in the range set by MS 2683: 2017 except for honey sample 2, which slightly higher $(218.66 \mathrm{mg} /$ $\mathrm{kg})$. HMF content in these samples was ranged between 8.78 to $218.66 \mathrm{mg} / \mathrm{kg}$. Based on Table 2,

Table 2. The physicochemical analysis of stingless bee honey

\begin{tabular}{lcccc}
\hline Test/sample & pH value & $\begin{array}{c}\text { Ash content } \\
(\mathrm{g})\end{array}$ & $\begin{array}{c}\text { Moisture Analyzer } \\
(\%)\end{array}$ & $\begin{array}{c}\text { Hydroxymethylfurfural } \\
(\mathrm{mg} / \mathrm{kg})\end{array}$ \\
\hline Sample 1 & $2.79 \pm 0.00^{\mathrm{e}}$ & $0.13 \pm 0.01^{\mathrm{a}}$ & $29.41 \pm 0.51$ & $25.75 \pm 1.90^{\mathrm{b}}$ \\
Sample 2 & $2.34 \pm 0.01^{\mathrm{g}}$ & $0.11 \pm 0.01^{\mathrm{bc}}$ & $27.05 \pm 1.39$ & $218.66 \pm 27.70^{\mathrm{a}}$ \\
Sample 3 & $2.70 \pm 0.01^{\mathrm{f}}$ & $0.13 \pm 0.00^{\mathrm{a}}$ & $28.04 \pm 1.88$ & $19.34 \pm 0.47^{\mathrm{b}}$ \\
Sample 4 & $2.92 \pm 0.01^{\mathrm{c}}$ & $0.14 \pm 0.01^{\mathrm{a}}$ & $27.20 \pm 0.22$ & $22.90 \pm 2.16^{\mathrm{b}}$ \\
Sample 5 & $2.92 \pm 0.01^{\mathrm{c}}$ & $0.12 \pm 0.01^{\mathrm{a}}$ & $29.21 \pm 2.70$ & $16.42 \pm 2.50^{\mathrm{b}}$ \\
Sample 6 & $2.97 \pm 0.00^{\mathrm{b}}$ & $0.12 \pm 0.01^{\mathrm{a}}$ & $29.99 \pm 0.90$ & $16.42 \pm 1.53^{\mathrm{b}}$ \\
Sample 7 & $3.22 \pm 0.02^{\mathrm{a}}$ & $0.10 \pm 0.00^{\mathrm{bc}}$ & $29.59 \pm 0.36$ & $12.38 \pm 1.77^{\mathrm{b}}$ \\
Sample 8 & $2.91 \pm 0.00^{\mathrm{c}}$ & $0.08 \pm 0.01^{\mathrm{bc}}$ & $27.96 \pm 2.39$ & $23.40 \pm 1.41^{\mathrm{b}}$ \\
Sample 9 & $2.87 \pm 0.01^{\mathrm{d}}$ & $0.11 \pm 0.00^{\mathrm{bc}}$ & $32.61 \pm 2.79$ & $19.41 \pm 3.83^{\mathrm{b}}$ \\
Sample 10 & $2.82 \pm 0.00^{\mathrm{e}}$ & $0.09 \pm 0.02^{\mathrm{bc}}$ & $32.19 \pm 0.34$ & $15.22 \pm 1.37^{\mathrm{b}}$ \\
Sample 11 & $2.81 \pm 0.00^{\mathrm{e}}$ & $0.10 \pm 0.00^{\mathrm{bc}}$ & $29.24 \pm 0.14$ & $10.98 \pm 2.91^{\mathrm{b}}$ \\
Sample 12 & $2.83 \pm 0.01^{\mathrm{e}}$ & $0.11 \pm 0.01^{\mathrm{bc}}$ & $27.61 \pm 3.20$ & $8.78 \pm 0.92^{\mathrm{b}}$ \\
Sample 13 & $2.87 \pm 0.01^{\mathrm{d}}$ & $0.14 \pm 0.01^{\mathrm{a}}$ & $29.78 \pm 1.81$ & $16.17 \pm 1.30^{\mathrm{b}}$ \\
\hline
\end{tabular}

$a, b, c, d, e, f$, and $g$ indicates the significant level $(p<0.05)$ for each of stingless bee honey, the sample with similar alphabet indicates not significant to each other. 
only honey sample 2 shows significant difference towards other samples. This means honey sample 2 was different from others. Hence, this finding was similarly mentioned by Islam et al. (2014) that the formation of HMF level was triggered by heating or preservation processes of honey. Heat treatment was used to remove yeast at a temperature below than $40^{\circ} \mathrm{C}$ for at least $30 \mathrm{~min}$ and may differ as time changes. Stingless bee honey contains high moisture, acidity, and fructose as predominance sugar leads to presents HMF formation resistance even after subjected to high temperatures. The variation of HMF content in honey was influenced by time and temperature conditions of honey stored in the hive before harvesting (Chuttong et al., 2016).

The highest and lowest moisture content identified was honey sample $9(32.61 \%)$ and 2 (27.05\%), respectively (Table 2). High moisture content may lead to honey fermentation caused by osmotolerant yeasts, thus affects the quality of honey by resulting in the formation of ethyl alcohol and carbon dioxide. The ethanol produce may break down into acetic acid and water, giving the honey a distinctly sour and a runny texture with small bubbles, surface heaving, or foaming (Moo-huchin et al., 2015). However, due to the high acidity of stingless bee honey, it may inhibit the presence and growth of microorganisms and prolong honey shelf life (Kek et al., 2017). In this study, the moisture content in all stingless bee honey was below the limit which complies with Malaysia Standard 2863:2017 except for sample 2. All samples showed different moisture content towards each other due to origin and honey sources. However, there was no significant difference observed $(p>0.05)$ using both methods.

\section{Microbial contaminant limit analysis}

The microbial contaminant limits of total plate count (TPC) were tabulated in Table 3 . From the result, $30.77 \%$ from samples $3,5,10$, and 11 were considered as contaminated with the microorganism of TPC $\left(5 \pm 7.07 \times 10^{2} \mathrm{CFU} / \mathrm{mL}\right)$. Most other samples were absent with the contamination of TPC might be due to the bacteria that cannot grow or reproduce in honey due to the presence of inhibitory properties in the stingless bee honey-like antibacterial or antimicrobial properties (Olaitan et al., 2007; Pucciarelli et al., 2014). However, samples 7 and 13 were free from the contamination of TPC bacteria since it was freshly harvested from their hive. Sample 10 is categorized as freshly harvested, but it still contaminated with TPC bacteria. According to Adenekan et al. (2010), fresh honey still have an opportunity to be contaminated due to improper handling and packaging process (Lani et al., 2017). Other factors that might contribute to the contamination of honey including primary sources such as pollen, nectar, digestive tracts of honey bees, dust, while secondary sources were including the air, handlers, cross-contamination, equipment, and buildings (Pucciarelli et al., 2014). In short, all samples complied with MS 2683:2017 specification for the contaminant limit in terms of total plate count.

\section{Enumeration of yeast and mold analysis}

The detection of contamination from yeast and mold in the stingless bee honey samples shown in Table 4. In this study, the contamination of yeast and mold detected in samples 4, 6, and 12. Sample 4 and 12 show a similar result with an average of $5.00 \pm 7.07 \mathrm{CFU} / \mathrm{mL}$, while sample 6 has an average of $10.00 \mathrm{CFU} / \mathrm{mL}$. By referring to MS 2683:2017 specification, the microbial contaminant limits of

Table 3. Microbial contaminant limit of total plate count (TPC) in stingless bee honey samples

\begin{tabular}{cc}
\hline Honey Samples & Microorganism count $(\mathrm{CFU} / \mathrm{mL})^{*}$ \\
\hline 1 & $<1.0 \times 10^{1 * *}$ \\
2 & $<1.0 \times 10^{1 * *}$ \\
3 & $5 \pm 7.07 \times 10^{2}$ \\
4 & $<1.0 \times 10^{1 * *}$ \\
5 & $5 \pm 7.07 \times 10^{2}$ \\
6 & $<1.0 \times 10^{1 * *}$ \\
7 & $<1.0 \times 10^{1 * *}$ \\
8 & $<1.0 \times 10^{1 * *}$ \\
9 & $<1.0 \times 10^{1 * *}$ \\
10 & $5 \pm 7.07 \times 10^{2}$ \\
11 & $5 \pm 7.07 \times 10^{2}$ \\
12 & $<1.0 \times 10^{1 * *}$ \\
13 & $<1.0 \times 10^{1 * *}$ \\
\hline
\end{tabular}

* Values represented as mean \pm std. deviation $(n=2)$.

** Plates with no CFU.

Table 4. Microbial contaminant limit of yeast and mold (YM) in stingless bee honey samples in CFU/mL

\begin{tabular}{cc}
\hline Honey Samples & Microorganism count $(\mathrm{CFU} / \mathrm{mL})^{*}$ \\
\hline 1 & $<1.0 \times 10^{1 * *}$ \\
2 & $<1.0 \times 10^{1 * *}$ \\
3 & $<1.0 \times 10^{1 * *}$ \\
4 & $5.00 \pm 7.07$ \\
5 & $<1.0 \times 10^{1 * *}$ \\
6 & 10.00 \\
7 & $<1.0 \times 10^{1 * *}$ \\
8 & $<1.0 \times 10^{1 * *}$ \\
9 & $<1.0 \times 10^{1 * *}$ \\
10 & $<1.0 \times 10^{1 * *}$ \\
11 & $<1.0 \times 10^{1 * *}$ \\
12 & $5.00 \pm 7.07$ \\
13 & $<1.0 \times 10^{1 * *}$
\end{tabular}

* Values represented as mean \pm std. deviation $(n=2)$.

** Plates with no CFU. 
yeast and mold are should less than $1 \times 10^{1} \mathrm{CFU} / \mathrm{mL}$. Thus, the quality of the contaminated samples 4 and 12 were still accepted since the value of CFU is not exceeding the limit, while only sample 6 was not qualified because exceeding the limit specified by MS 2683:2017. The result also shows that microbial contaminant limits of yeast and mold were not significant $(p<0.05)$ among the 13 samples of the stingless bee honey.

\section{Determination of total coliform analysis}

The specification of Malaysian Standard (MS) 2683:2017 has established a standard for the acceptable limit of total coliforms in stingless bee honey for consumer consumption with a value of less than $1 \times 10^{1} \mathrm{CFU} / \mathrm{mL}$. The commercial stingless bee honey shall not contain the total coliform exceeding the limits specified in the guideline. In this study, total coliform was not detected in any of the 13 samples of stingless bee honey. All samples collected from different locations of Kelantan can be categorized as free from the total coliform since the sample is absent from total coliform contamination due to the good ecological condition and hygiene.

\section{CONCLUSION}

In summary, all samples of stingless bee honey-do comply with MS 2683:2017 specification for physicochemical properties and microbial contaminant limits of total plate count (TPC) and total coliform. However, for the microbial contaminant limit of yeast and mold, only sample 6 was contaminated. $92.31 \%$ of stingless bee honey collected from different locations of Kelantan was in good quality without any adulteration from other species of bees or the addition of sugar syrup.

\section{ACKNOWLEDGEMENTS}

The authors would like to acknowledge to the Ministry of Education, Malaysia, for research grant: (R/FRGS/A07.00/00760A/004/2016/000366), Faculty of Agro Based Industry, Universiti Malaysia Kelantan, Kampus Jeli.

\section{REFERENCES}

Adenekan, M.O., Amusa, N.A., Lawal, A.O. \& Okpeze, V.E. 2010. Physicochemical and microbiological properties of honey samples obtained from Ibadan. Journal of Microbiology and Antimicrobials, 2(8): 100-104.
Ananias, K.R., de Melo, A.A.M. \& de Moura, C.J. 2013. Analysis of moisture content, acidity, and contamination by yeast and molds in Apis mellifera L. honey from central Brazil. Brazilian Journal of Microbiology, 44(3): 679-683.

Biswa, R., Sarkar, A. \& Subba, S.K. 2017. Ethnomedicinal uses of honey of stingless bee by Nepali community of Darjeeling foothills of West Bengal, India. NISCAIR-CSIR, India. pp. 648-653.

Buba, F., Gidado, A. \& Shugaba, A. 2013. Physicochemical and microbiological properties of honey from North-East Nigeria. Biochemistry \& Analytical Biochemistry, 2(4): 1-7.

Chuttong, B., Chanbang, Y., Sringarm, K. \& Burgett, M. 2016. Effects of long-term storage on stingless bee (Hymenoptera: Apidae: Meliponini) honey. Journal of Apicultural Research, 8839: $1-10$.

Da Silva, P.M., Gauche, C., Gonzaga, L.V., Costa, A.C.O. \& Fett, R. 2016. Honey: Chemical composition, stability, and authenticity. Food Chemistry, 196: 309-323.

Fadzelly, A.B., Shuaibu Babaji, S., Fazleen Izzany, A.B., Cong, O.J. \& Zakbah, M. 2017. Physicochemical and antioxidant potential of raw unprocessed honey from Malaysian stingless bees. Pakistan Journal of Nutrition, 16(11): 888-894.

Fatima, I., Mohd Hilmi, A., Salwani, I. \& Lavaniya, M. 2018. Physicochemical characteristics of Malaysian Stingless Bee Honey from Trigona Species. International Medical Journal Malaysia, 17(1): 187-191.

Islam, M.N., Khalil, M.I., Islam, M.A. \& Gan, S.H. 2014. Toxic compounds in honey. Journal of Applied Toxicology, 34(7). 733-742.

Kek, S.P., Chin, N.L., Yusof, Y.A., Tan, S.W. \& Chua, L.S. 2017. Classification of entomological origin of honey-based on its physicochemical and antioxidant properties. International Journal of Food Properties, 20(3): S2723S2738.

Lani, M.N., Zainudin, A.H., Abdul, S.B., Mansor, A. \& Hassan, Z. 2017. Microbiological quality and $\mathrm{pH}$ changes of honey produced by Stingless Bees, Heterotrigona itama and Geniotrigona thoracica stored at ambient temperature. Malaysian Applied Biology, 46(3): 89-96.

Malaysian Standard MS 2683/: 2017. 2017. Kelulut (Stingless bee) honey - Specification. Department of Standard Malaysia. pp. 2683.

Moo-huchin, V.M., González-aguilar, G.A., Liramaas, J.D. \& Pérez-pacheco, E. 2015. Physicochemical properties of Melipona beecheii honey of the Yucatan. Journal of Food Research, 4(5): 24-32. 
Olaitan, P.B., Adeleke, O.E. \& Ola, I.O. 2007. Honey: a reservoir for microorganisms and an inhibitory agent for microbes. African Health Sciences, 7(3): $159-165$.

Pucciarelli, A.B., Schapovaloff, M.E., Kummritz, S. \& Señuk, I.A. 2014. Microbiological and physicochemical analysis of yateí (Tetragonisca angustula) honey for assessing quality standards and commercialization. Revista Argentina de Microbiología, 46(4): 325-332.

Suntiparapop, K., Prapaipong, P. \& Chantawannakul, P. 2012. Chemical and biological properties of honey from Thai stingless bee (Tetragonula leaviceps). Journal of Apicultural Research, 51(1): 45-52.
Ummulkhair, M. 2014. Microbiological evaluation of commercial honey from Edo State, Nigeria. International Journal of Scientific \& Engineering Research, 5(12): 796-799.

Zainol, M.I. 2016. Study on Antioxidant Capability, Antibacterial Activity, Phenolic Profile and Microbial Screening of Selected Malaysian and Turkish Honey (Master). University of Malaya. 